\title{
Giant Serpentine Cerebral Aneurysm of the Middle Cerebral Artery: Case Report
}

\author{
Abdulrahman M. Al Shamy', Mohammed D. Alsahafi' ${ }^{2}$, Muhammed A. Alghamdi², \\ Abdullah A. Alshamrani2, Roaa N. Filfilan² \\ ${ }^{1}$ Radiology Department, KAMC-NG, Jeddah, KSA \\ ${ }^{2}$ College of Medicine, Umm Alqura University, Makkah, KSA \\ Email: M.D.Alsahafi@gmail.com
}

How to cite this paper: Al Shamy, A.M., Alsahafi, M.D., Alghamdi, M.A., Alshamrani, A.A. and Filfilan, R.N. (2017) Giant Serpentine Cerebral Aneurysm of the Middle Cerebral Artery: Case Report. Open Journal of Medical Imaging, 7, 9-16. https://doi.org/10.4236/ojmi.2017.71002

Received: February 5, 2017

Accepted: February 18, 2017

Published: February 21, 2017

Copyright $\odot 2017$ by authors and Scientific Research Publishing Inc. This work is licensed under the Creative Commons Attribution International License (CC BY 4.0).

http://creativecommons.org/licenses/by/4.0/

\begin{abstract}
A 43-year-old male presented with severe intermittent headaches since two years accompanied by multiple episodes of generalized seizures and left hand weakness. MRI scan and cerebral angiography confirmed the diagnosis of a giant serpentine cerebral aneurysm arising from the middle cerebral artery. The patient was admitted for a possible cerebral embolization after undergoing a Balloon Occlusion Test (BOT). Since he tolerated the occlusion test, he underwent coil embolization afterwards with successful occlusion followed by an uneventful recovery and no complications. Later on, the patient was discharged home in a stable and good general condition without any neurological deficits. A six-month angiography follow-up revealed a complete occlusion with no re-canalization of the coiled giant serpentine aneurysm. Therefore, we concluded that parent artery occlusion is a good and safe procedure providing that the patient tolerated both the occlusion and the hemodynamic stress tests.
\end{abstract}

\section{Keywords}

Aneurysm, Giant, Interventional Neuroradiology, Giant Serpentine

Aneurysm, Balloon Occlusion Test, Parent Artery Sacrifice, Coil

Embolization, Endovascular

\section{Introduction}

Giant Serpentine Aneurysms (GSAs) are extremely rare aneurysms with unique radiological and pathological features [1]. They are giant, usually partially thrombose aneurysms with a diameter greater than $25 \mathrm{~mm}$ and are characterized by the presence of a snake-like channel between the inflow and outflow of the aneurysm [2] [3] [4]. In 1977, they were first described by Segal and McLaurin 
[5] as a different entity from intracranial saccular aneurysms in which they lack a discrete identifiable neck [6]. Patients with Giant Serpentine Aneurysms may complain of headache, seizures, upper or lower limbs weakness and many other symptoms depending on the location of the aneurysm, which usually occurs in the Middle Cerebral Artery (MCA) [7] [8]. These clinical features combined with the Computerized Tomography (CT) and Magnetic Resonance Imaging (MRI) results can be easily mistaken for cerebral neoplasms. An early diagnosis of Giant Cerebral Aneurysm by cerebral angiography is critical. The goal of GSAs treatment is to stop the growth, reduce and alleviate the mass effect symptoms and to obliterate the abnormal serpiginous vascular structure. Here, we present a case of Giant Serpentine Aneurysm of the Middle Cerebral Artery in a 43-year-old male who complained of severe intermittent headaches for two years with left hand weakness and multiple episodes of generalized seizures. The patient was treated with occlusion of the parent artery by coils after tolerating the Balloon Occlusion Test.

\section{Case Report}

A 43-year-old male was referred to King Abdulaziz Medical City-National Guard (KAMC-NG) Hospital complaining of severe headache. He had a twoyear history of intermittent headaches that had gradually worsened over the past three months. Moreover, he had experienced multiple episodes of generalized seizures and complained of dizziness, easy fatiguability and left hand weakness. There was no vomiting or loss of consciousness. The patient was known to have diabetes and hypertension on treatment. Furthermore, his surgical history was positive for appendectomy. Regarding his physical examination on admission, he was conscious, alert, oriented with GCS $15 / 15$ and vitally stable. A CT without contrast was done in another hospital which revealed a suspected right temporal fossa arteriovenous malformation with no hemorrhage and no significant edema. After that, a follow-up MRI scan showed a right temporal space-occupying lesion measuring $2.7 \times 3.8 \mathrm{~cm}$ with an evidence of tubular signal void structure within it, raising the possibility of a partially thrombosed aneurysm of the right Middle Cerebral Artery (MCA) associated with peri-lesional edema. Later on, an angiography displayed an abnormal tortuous channel arising from the superior branch of the MCA reflecting the patent channel within the GSA with relative hypo-perfusion on the surrounding temporoparietal region (Figure $1)$.

For that, the option of occlusion of this Giant Serpentine Aneurysm was considered. Risks and benefits were discussed with the patient. Then he was admitted for cerebral angiogram with Balloon Occlusion Test for twenty minutes, which revealed no neurological deficits. Afterwards, hemodynamic stress test was performed by dropping the mean B.P. by $10 \%$ which the patient also tolerated with no clinical symptoms. Because of that, we decided to proceed with the parent artery sacrifice. This procedure was initiated by navigating a micro-catheter to the distal aspect of the GSA. Additionally, a compliant balloon 

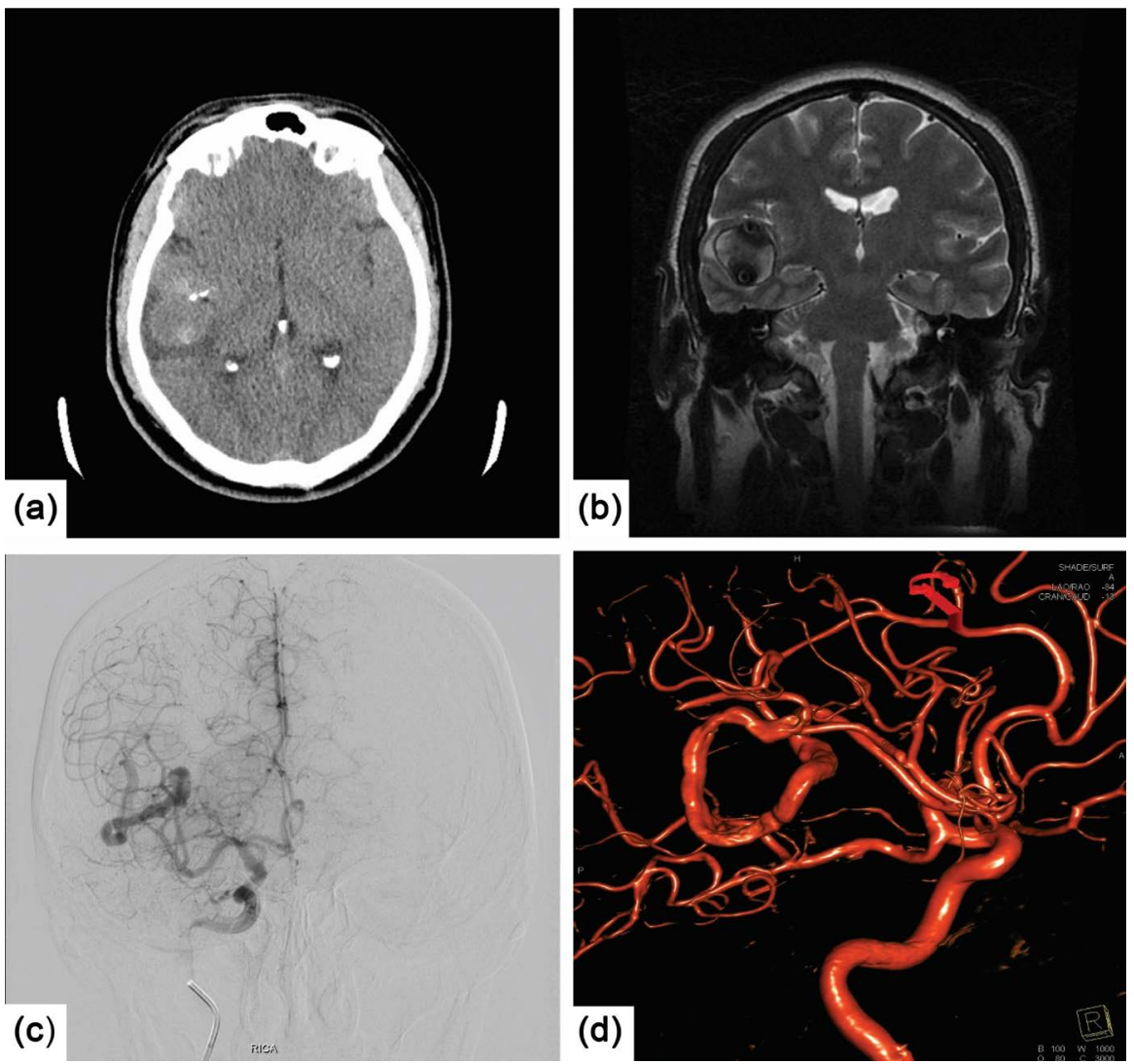

Figure 1. Diagnostic imaging. (a) CT scan without contrast shows a right temporal lobe mass with small calcification and perilesional edema; (b) Coronal T2-weighted MRI shows the space occupying lesion with small rounded structure within signal void area; (c) Frontal view; and (d) 3D view catheter cerebral angiogram shows an abnormal tortuous channel arising from the superior branch of the right MCA confirming the diagnosis of GSA.

was inflated and coils were progressively deployed until a complete occlusion of the GSA was achieved (Figure 2).

The patient tolerated the procedure well and was transferred to ICU for a one-day observation. Since his recovery was uneventful with no neurological deficit, he was transferred to a regular ward the next day. An MRI scan follow-up was done and showed no change in the perilesional edema (Figure 3). Meanwhile, Dexamethasone was administered from day one with a dose of $3 \mathrm{mg}$, three times a day for three days and then tapered down over one week.

The patient was discharged home in a stable and good general condition without any neurological deficits. A six-month angiography follow-up revealed a complete occlusion with no re-canalization of the coiled Giant Serpentine Aneurysm (Figure 4).

\section{Discussion}

In a literature review done by Aletich et al. [2] on 33 cases of GSAs, it was stated that these aneurysms have been identified on the Middle Cerebral Artery or its branch vessels in $51 \%$ of the patients, the vertebral artery in $18 \%$, the posterior 
cerebral artery in $12 \%$, the internal carotid artery in $12 \%$, the anterior cerebral artery in $3 \%$, and the posterior communicating artery in $3 \%$. In our case, the serpentine aneurysm involved the superior branch of the Middle Cerebral Artery.

The presentation of these aneurysms depends on the location, but they usually
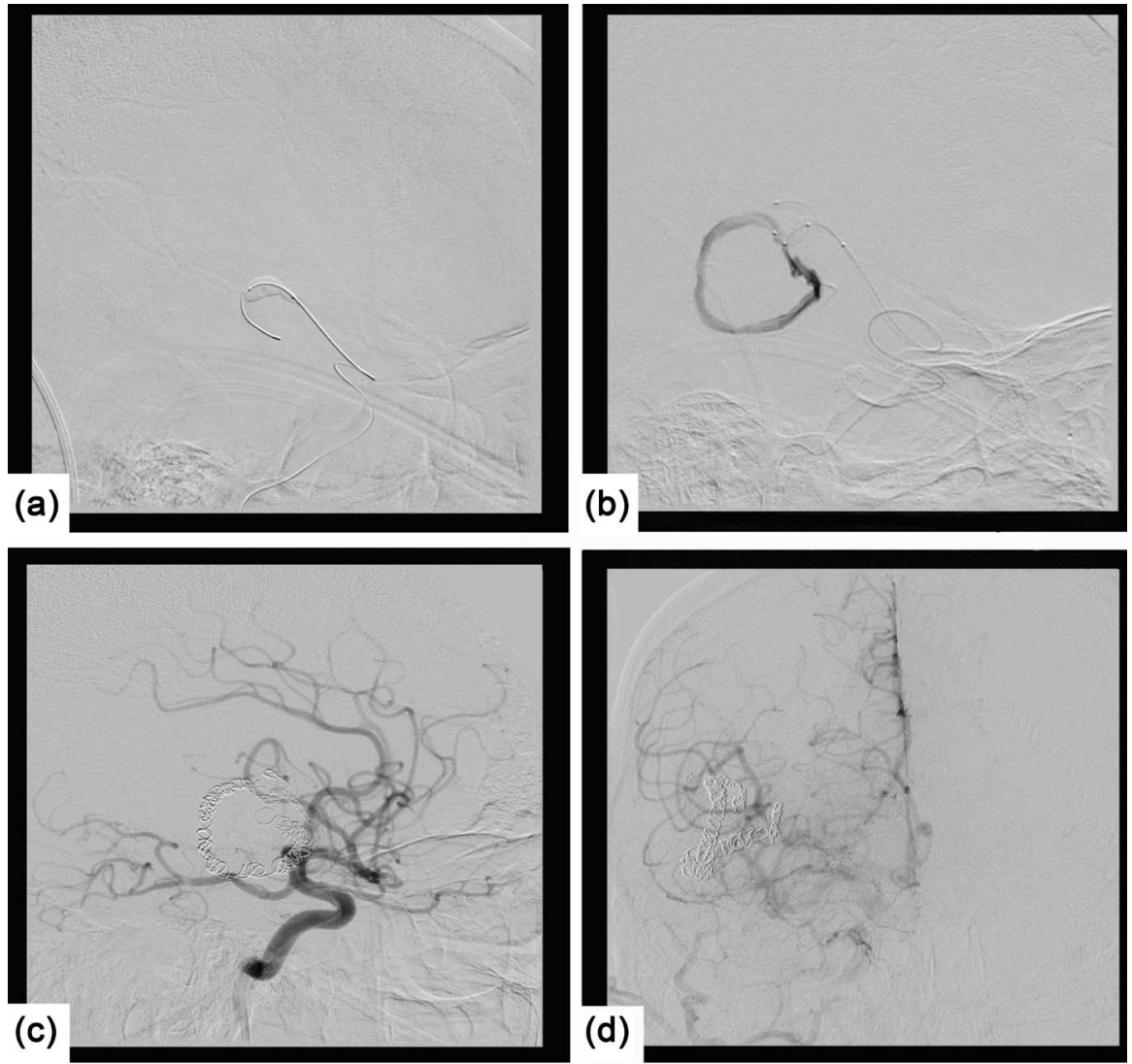

Figure 2. Embolization angiogram: (a) Balloon occlusion test; (b) Proximal micro-catheter with balloon, the second in the distal aspect of the GSA; (c) Lateral view; (d) Frontal view post-embolization cerebral angiogram showing complete occlusion of the lesion.
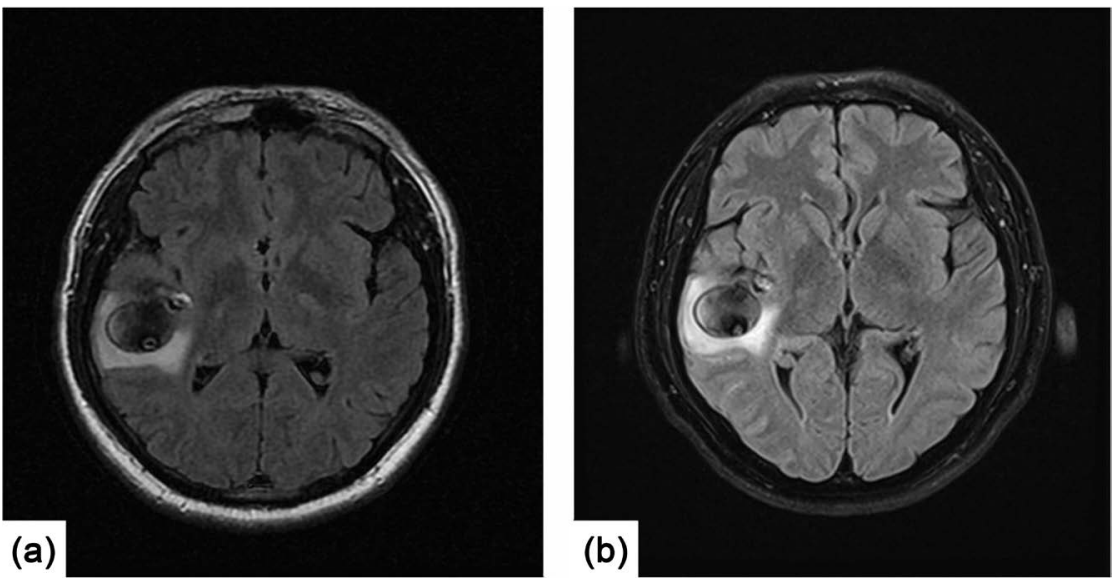

Figure 3. FLAIR axial view MRI pre and post embolization: (a) Pre-embolization shows central signal void and perilesional edema; (b) Post-embolization demonstrates loss of the central signal void and stable perilesional edema. 

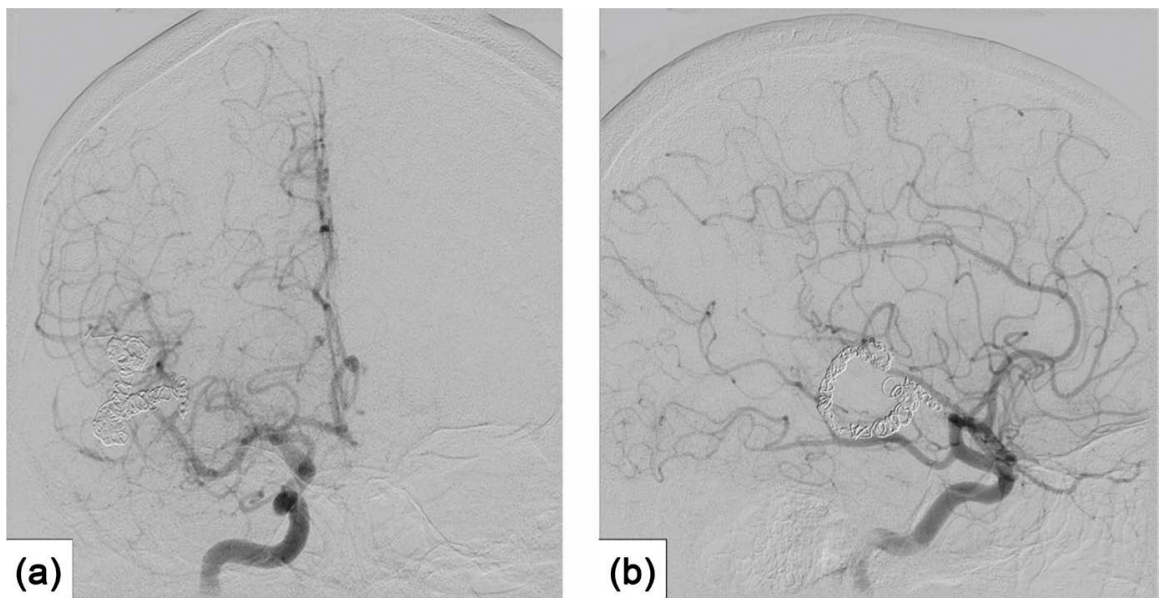

Figure 4. Six-month follow-up angiogram: (a) Frontal view; (b) Lateral view show a complete occlusion with no re-canalization of the GSA.

manifest as intracranial masses rather than intracranial hemorrhage, which are frequently seen by CT and MR imaging studies that could show a mass effect with an associated edema [1] [2] [9]. Therefore, they can be mistaken for neoplasms and further cerebral angiography will be needed to confirm the diagnosis [1] [10]. The predominant signs and symptoms include headaches, hemiparesis, visual disturbances, cranial nerve palsies, dysphasia and aphasia, nausea, vomiting, seizure and vertigo [2] [9] [11]. Rarely, it can present with acute subarachnoid hemorrhage as reported by Suzuki et al. [7]. In our case, the patient presented with intermittent headaches, dizziness, easy fatiguability, generalized seizures and left hand weakness.

The natural history of these aneurysms has a wide variety as noted in the literature review. For instance, there are some reports [1] [2] [12] [13] [14] [15] that proclaimed these lesions remained static while others have reported spontaneous occlusions of these lesions which may be followed by re-canalization. Then again, many other case reports have documented continuous growth of aneurysms with acute deterioration [6] [15]. Therefore, treatment of this rare condition is of crucial importance.

The pathogenesis and the reason of forming GSAs is yet uncertain. Indeed, some reports have linked GSAs with preexisting fusiform [16] [17] [18] or saccular aneurysms [19] [20] [21] [22] that progressed over time to form serpentine aneurysms. Moreover, other reports have hypothesized that hyperglycemia and inflammatory process of the adventitia may help in the formation of these aneurysms [6]. Serpentine aneurysms tend to favor the middle cerebral artery due to the absence of structures that limit the growth of the aneurysm in comparison with the inferior cerebral artery which is surrounded with bony and dural structures [23].

In CT scans, GSAs may mimic a tumor as it can be seen as a well circumscribed lesion that shows heterogeneous enhancement and could be associated with edema and midline shifting [22]. In fact, catheter angiography is the best modality in identifying the site of the lesion and the size of the serpentine aneu- 
rysm [10].

Generally, Giant Serpentine Aneurysms are challenging lesions to treat. Although this may be true, there are several ways to treat GSAs with the aim to exclude the abnormal vascular channel from the circulation, arrest their growth, thus, eliminating the mass effect. This can be achieved by the direct and permanent occlusion of the parent artery at the origin of the aneurysm [10]. That is to say, treatment options mainly include surgical or endovascular interventions; sometimes both of them can be performed together [24]. Open surgical approaches include intracranial bypass and proximal and/or distal clipping, aneurysm resection/reconstruction, or carotid ligation [7] [23] [25] [26] whereas endovascular techniques range from parent artery sacrifice to direct embolization of the GSA with coils, balloons, or liquid embolic agents [3] [9].

The treatment choice depends on the location, size, morphology and surgical accessibility of the aneurysm, as well as the clinical presentation and the age of the patient [11] [23]. It is also important to evaluate intracranial hemodynamics and perform a careful functional testing of the distal territory before definitive therapy of the aneurysm. This can be determined by an endovascular Balloon Occlusion Test (BOT); the balloon will temporarily occlude the entrance channel to the aneurysm and the patient's neurologic status will be closely monitored. If any changes in the neurological status were observed, that indicates the vascular channel supplies vital distal branches of the parent artery without sufficient collateral filling of the distal vasculature which necessitates a functional bypass procedure to improve the blood supply to the affected hemisphere before performing an endovascular occlusion of the parent artery [6]. Sub-selective injections of amobarbital into the aneurysm may provide complimentary information to the BOT [2] especially in case of terminal branch aneurysm. If the BOT and amobarbital tests were negative, that means the outflow pathway of the serpentine channel does not supply vital brain parenchyma and distal cerebral vessels, and permanent occlusion can be done with detachable balloons, liquid polymerizing agents or coils. In our case, the superior branch of right MCA was occluded with a balloon for 20 minutes. During the occlusion, the patient was neurologically stable with no signs of clinical deterioration. Therefore, the patient was tested further by a hemodynamic stress test where his mean BP was decreased by $10 \%$ which he also tolerated well. For that reason, we decided to do the coil embolization with balloon occlusion protection, avoiding aneurysm hemodynamic change. This procedure required double femoral arteries puncture with a second guiding catheter and navigation of a micro-catheter into the distal aspect of the aneurysm. Before deploying the coils, the balloon was inflated and a progressive coil embolization from distal to proximal was done. Afterall, the procedure showed a successful improvement of the patient's clinical condition.

\section{Conclusion}

As has been noted, the application of the balloon occlusion and the hemodynamic stress tests, followed by a parent artery sacrifice by coiling was a success- 
ful and safe treatment method for GSAs given that the patient had tolerated the procedure. This approach immediately relieved symptoms related to the mass effect in our patient.

\section{Acknowledgements}

We would like to thank Dr. Nuha Filfilan-Public Health and Preventive Medicine resident-for her assistance with the language editing and proof reading that greatly improved our manuscript.

\section{Consent}

Permission for the case report to be published was obtained from the patient during one of the follow-up visits.

\section{Conflicts of Interest}

The authors declare that no competing interests exist.

\section{References}

[1] Coley, S.C., Hodgson, T.J. and Jakubowski, J. (2002) Coil Embolization of Giant Serpentine Aneurysms: Report of Two Cases Arising from the Posterior Cerebral Artery. British Journal of Neurosurgery, 16, 43-47.

https://doi.org/10.1080/02688690120114219

[2] Aletich, V.A., Debrun, G.M., Monsein, L.H., Nauta, H.J.W. and Spetzler, R.F. (1995) Giant Serpentine Aneurysms: A Review and Presentation of Five Cases. American Journal of Neuroradiology, 16, 1061-1072.

[3] Grandhi R., Williamson, R.W., Zwagerman, N.T. and Hanel, R.A. (2016) Giant Serpentine Aneurysm. BMJ Case Reports, 2016, 2015-2016. https://doi.org/10.1136/bcr-2015-212019

[4] Choudhary, P., Khokhar, H.V. and Saxena, S. (2015) Giant Serpentine Vertebrobasilar Aneurysm with Vertebral Artery Hypoplasia and Fenestration-A Case Report. Journal of Clinical and Diagnostic Research, 9, TD01-TD02.

[5] Segal, H.D. and McLaurin, R.L. (1977) Giant Serpentine Aneurysm. Report of Two Cases. Journal of Neurosurgery, 46, 115-120. https://doi.org/10.3171/jns.1977.46.1.0115

[6] Zampakis, P., Papanastasiou, V., Devine, J. and Bhattacharya, J. (2007) Giant Serpentine Aneurysm in a Patient with Multiple Endocrine Neoplasia Type 1 Syndrome. Interventional Neuroradiology, 13, 95-100. https://doi.org/10.1177/159101990701300113

[7] Suzuki, S., Takahashi, T., Ohkuma, H., Shimizu, T. and Fujita, S. (1992) Management of Giant Serpentine Aneurysms of the Middle Cerebral Artery-Review of Literature and Report of a Case Successfully Treated by STA-MCA Anastomosis Only. Acta Neurochirurgica (Wien), 117, 23-29. https://doi.org/10.1007/BF01400630

[8] Christiano, L.D., Gupta, G., Prestigiacomo, C.J. and Gandhi, C.D. (2009) Giant Serpentine Aneurysms. Neurosurgical Focus, 26, E5.

https://doi.org/10.3171/2009.2.FOCUS0918

[9] Park, J.S., Lee, M.S., Kim, M.S., Kim, D.J., Park, J.W. and Whang, K. (2001) Giant Serpentine Intracranial Aneurysm: A Case Report. Korean Journal of Radiology, 2, 179-182. https://doi.org/10.3348/kjr.2001.2.3.179 
[10] Pany, A., Sobri, M., Valarmathi, S. and Latif, A.Z. (2004) Giant Serpentine Middle Cerebral Artery Aneurysm. Medical Journal of Malaysia, 59, 422-424.

[11] Jaworska, K., Dołowy, J., Kuśmierska, M., Kuniej, T. and Jaźwiec, P. (2012) Multiple Fusiform Cerebral Aneurysms-Case Report. Polish Journal of Radiology, 77, 50 53. https://doi.org/10.12659/PJR.882581

[12] Kim, H.J., Kim, J.H., Kim, D.R. and Kang, H.I. (2014) Thrombosis and Recanalization of Small Saccular Cerebral Aneurysm: Two Case Reports and a Suggestion for Possible Mechanism. Journal of Korean Neurosurgical Society, 55, 280-283. https://doi.org/10.3340/jkns.2014.55.5.280

[13] Sari, A., Kandemir, S., Kuzeyli, K. and Dinc, H. (2006) Giant Serpentine Aneurysm with Acute Spontaneous Complete Thrombosis. American Journal of Neuroradiology, 27, 766-768.

[14] Lee, K.C., Joo, J.Y., Lee, K.S. and Shin, Y.S. (1999) Recanalization of Completely Thrombosed Giant Aneurysm: Case Report. Surgical Neurology, 51, 94-98. https://doi.org/10.1016/S0090-3019(97)00346-7

[15] Mahadevan, A., Tagore, R., Siddappa, N.B., et al. (2008) Giant Serpentine Aneurysm of Vertebrobasilar Artery Mimicking Dolichoectasia-An Unusual Complication of Pediatric AIDS. Report of a Case with Review of the Literature. Clinical Neuropathology, 27, 37-52. https://doi.org/10.5414/NPP27037

[16] Tomasello, F., Albanese, V. and Cioffi, F.A. (1979) Giant Serpentine Aneurysms: A Separate Entity. Surgical Neurology, 12, 429-432.

[17] Ammerman, B.J. and Smith, D.R. (1977) Giant Fusiform Middle Cerebral Aneurysm: Successful Treatment Utilizing Microvascular Bypass. Surgical Neurology, 7, 255-257.

[18] Terada, Y., Tomita, K., Shinoda, T., Iino, Y. and Yoshiyama, N. (1988) Giant Serpentine Aneurysm in a Long-Term Hemodialysis Patient. Clinical Nephrology, 30, 164-167.

[19] Sadik, A.R., Budzilovich, G.N. and Shulman, K. (1965) Giant Aneurysm of Middle Cerebral Artery: A Case Report. Journal of Neurosurgery, 22, 177-181. https://doi.org/10.3171/jns.1965.22.2.0177

[20] Bull, J. (1969) Massive Aneurysms at the Base of the Brain. Brain, 92, 535-570. https://doi.org/10.1093/brain/92.3.535

[21] Morley, T.P. and Barr, H.W. (1969) Giant Intracranial Aneurysms: Diagnosis, Course, and Management. Clinical Neurosurgery, 16, 73-94.

[22] Lukin, R.R., Chambers, A.A., McLaurin, R. and Tew, J.J. (1975) Thrombosed Giant Middle Cerebral Aneurysms. Neuroradiology, 10, 125-129.

https://doi.org/10.1007/BF00341812

[23] Lee, S.J., Ahn, J.S., Kwun, B.D. and Kim, C.J. (2010) Giant Serpentine Aneurysm of the Middle Cerebral Artery. Journal of Korean Neurosurgical Society, 48, 177-180. https://doi.org/10.3340/jkns.2010.48.2.177

[24] Kim, S.T., Jeong, Y. and Jeong, H.W. (2016) Treatment of a Giant Serpentine Aneurysm in the Anterior Cerebral Artery. Journal of Cerebrovascular and Endovascular Neurosurgery, 18, 141-146.

[25] Scott, M. and Skwarok, E. (1961) The Treatment of Cerebral Aneurysms by Ligation of the Common Carotid Artery. Surgery, Gynecology \& Obstetrics, 113, 54-61.

[26] Amin-Hanjani, S., Chen, P.R., Chang, S.W. and Spetzler, R.F. (2006) Long-Term Follow-Up of Giant Serpentine MCA Aneurysm Treated with EC-IC Bypass and Proximal Occlusion. Acta Neurochirurgica, 148, 227-228.

https://doi.org/10.1007/s00701-005-0691-3 
Submit or recommend next manuscript to SCIRP and we will provide best service for you:

Accepting pre-submission inquiries through Email, Facebook, LinkedIn, Twitter, etc. A wide selection of journals (inclusive of 9 subjects, more than 200 journals)

Providing 24-hour high-quality service

User-friendly online submission system

Fair and swift peer-review system

Efficient typesetting and proofreading procedure

Display of the result of downloads and visits, as well as the number of cited articles Maximum dissemination of your research work

Submit your manuscript at: http://papersubmission.scirp.org/

Or contact ojmi@scirp.org 